\title{
RETIREMENT VILLAGE RESIDENT DURATION AN EMPIRICAL ANALYSIS
}

\author{
Lois Towart \\ University of Technology, Sydney
}

\begin{abstract}
In Australia retirement villages are occupied under a number of tenures of which the common feature is the fee structure whereby a resident initially purchases their right to occupy and at the end of their tenure pays an amount based on variable factors to the owner/operator of the village. As the owner/operator receives their return at the end of residents' tenure the return can only be estimated based on projections including the tenure of the resident and increase in sale price of units. This paper presents original research into valuation metrics including the length of resident tenure (duration) over a 27 year period.
\end{abstract}

Keywords: Retirement Village, Resident Duration, Valuation Metrics

\section{INTRODUCTION}

Specialised accommodation for seniors in Australia comprises two main products, Retirement Villages, and Residential Aged Care Facilities. Retirement Villages accommodate residents who are able to live independently in the community and the sector is regulated at the State level; Residential Aged Care Facilities are for those who have been identified as requiring medical care and personal assistance and these are regulated at the Commonwealth level (Towart 2005). Occupancy in Australian retirement villages can be under a number of different types of tenure including Leasehold, Strata Title (Freehold), Loan and/or Licence and Rental (Cradduck and Blake 2012). Practice based industry observation has noted additional tenure types of Unit Title in the Australian Capital Territory and Company Title.

With the exception of rental tenure, which is occupied under State residential tenancies legislation, retirement villages are operated under State legislation with each State and Territory having their own individual Retirement Village Act and Regulations (detailed in Table 1). A feature across all jurisdictions is that a retirement village resident occupies their unit under a contractual agreement with the village operator (Resident Contract). This provides the right for that resident to live in the village; the resident agrees to pay the operator for this right and the elements of this fee arrangement are detailed in this document.

Village residents pay an incoming contribution (purchase) to the operator or the previous occupant of the unit, this price is usually at a discount to prices for commensurate accommodation on the open market. At the end of the period of occupancy residents pay the owner/operator of the village a Deferred Management Fee (DMF) this fee is agreed to in the Resident Contract and may be calculated on a number of variable factors (Elliott, Earl and Reid 2002; McAuliffe 2010).

The main components of the DMF include:

- A percentage per annum, which may be variable, reaching a cumulative maximum from $20 \%$ to $45 \%$ over 5 to 10 years of the period of occupancy (McAuliffe 2010). Practice based industry observation has noted cumulative maximums as low as $10 \%$ and periods up to 12 years. This is multiplied by either the incoming contribution of that resident or the incoming contribution of the next resident; and

- A share of the difference in price between the incoming contribution of that resident and the incoming contribution of the next resident, referred to as the capital gain. This share may be between $0 \%$ and $100 \%$. 
The Resident Contract may also include responsibility for the sharing of the cost of the refurbishment of the unit on vacating and marketing expenses/sales commissions in attracting the next resident. In addition to the DMF, residents also pay an ongoing monthly services charge for rates, insurance, security and other village services; under most State legislation this is limited to a cost recovery basis.

\begin{tabular}{ll}
\hline State/Territory & Legislation \\
\hline $\begin{array}{l}\text { Australian Capital } \\
\text { Territory }\end{array}$ & Retirement Villages Act 2012 (ACT) \\
\hline New South Wales & $\begin{array}{l}\text { Retirement Villages Act 1999 (NSW) } \\
\text { Retirement Villages Regulations 2009 (NSW) }\end{array}$ \\
\hline Northern Territory & $\begin{array}{l}\text { Retirement Villages Act 1995 (NT) } \\
\text { Retirement Villages Regulations (NT) }\end{array}$ \\
\hline Queensland & $\begin{array}{l}\text { Retirement Villages Act 1999 (Qld) } \\
\text { Retirement Villages Regulations 2010 (Qld) }\end{array}$ \\
\hline South Australia & $\begin{array}{l}\text { Retirement Villages Act 1987 (SA) } \\
\text { Retirement Villages Regulations 2006 (SA) }\end{array}$ \\
\hline Tasmania & $\begin{array}{l}\text { Retirement Villages Act 2004 (Tas) } \\
\text { Retirement Villages Regulations 2005 (Tas) }\end{array}$ \\
\hline Victoria & $\begin{array}{l}\text { Retirement Villages Act 1986 (Vic) } \\
\text { Retirement Villages (Contractual Arrangements) Regulations 2006 } \\
\text { (Vic) } \\
\text { Retirement Villages (Records and Notices) Regulations 2005 (Vic) }\end{array}$ \\
\hline Western Australia & $\begin{array}{l}\text { Retirement Villages Act 1992 (WA) } \\
\text { Retirement Villages Regulations 1992(WA) }\end{array}$ \\
\hline
\end{tabular}

\section{Retirement Village Legislation \\ Table 1}

On completion of the development of individual village units the first residents to occupy these new units are the initial residents, so for any one unit there is only one initial resident. Following the exit of these initial residents the units are then resold to rollover residents, therefore there can be a multiple of sequential rollover residents for any one unit. Following completion of the development of a village the initial sales contribute to the development proceeds, the ongoing return is received by the owner/operator of the village when an individual resident departs. This return is based on a calculation (agreed to in the Resident Contract) of a cumulative percentage per annum depending on how long the resident was in the village multiplied by the initial entry price and/or the entry price of the next incoming resident (Moshione 1992, Hatcher and O’Leary 1994).

In undertaking a cash flow of these returns the difficulty then arises is to predict the timing of the individual resident departure. Valuation practice is to calculate this departure for current residents (in occupancy) on actuarial life tables based on the age of the resident cross referenced with their period of occupancy. As personal information is known for current residents these departures can be predicted with a reasonable level of comfort (Armitage et al 2002). Furthermore as village 
residents may not necessarily pass away in the village but move to a Residential Aged Care Facility or hospital for their final mile this projected resident departure is reduced by an $\mathrm{x}$ factor (Hatcher and O’Leary 1994, McAuliffe 2012).

The difficulty arises to predict the timing of the departure of future residents, as these have not yet moved into the village therefore their personal details are not yet known. The projected duration (period of occupancy) for all future residents can be based on an average number of years (Hatcher and O’Leary 1994, McAuliffe 2012). Moreover this creates problems in applying a single average to a range of probable durations. This solution has been the application of Monte Carlo simulations which allows for a range of probabilities to be assigned to these future durations. This analysis will quantify benchmarks which can be utilised by valuers and village owners/operators and to establish whether this duration distribution follows a skewed or normal distribution.

\section{LITERATURE REVIEW}

The principal method of valuation of an operational retirement village utilises Discounted Cash Flow (DCF) analysis as this method is suited to the lumpiness of a village's projected cash flows, however this method is dependent upon the veracity of the underlying assumptions (Hatcher and O'Leary 1994, McAuliffe 2012). These assumptions include: a prediction as to the length of residency (duration) for individual residents both current and future; the type of DMF structure both current and future; the period of vacancy between a resident leaving and a new resident entering; and the capital growth of the value of units in the village and hence the future contributions paid by incoming residents (Towart 2009).

A significant component of a retirement village DCF is the timing and quantum of the DMF receipts. While the anticipated departure date can be estimated from the current residents as discussed previously, estimating the duration of future residents requires the application of an average number of years; the determination of which is based on operators' analysis of operational history and valuers' professional opinion. Larger operators are able to calculate resident duration based on their existing portfolio which may include villages under construction, maturing and mature. This paper addresses the lack of quantifiable research into the average resident duration for both initial residents, those occupying a new unit, and rollover residents, those occupying a previously occupied unit, and whether these durations profile in a normal distribution or a skewed distribution.

The factors that determine any individual duration include the residents' age, gender, personal history and their health, and whether they are single or a couple, this requires additional information which is only available at considerable cost and is more suited to further analysis.

The Monte Carlo approach in DCF valuations addresses the issue of uncertainty in valuations; this approach allows the valuer to ascertain a range of outcomes for the most important variables within the valuation and to ascribe probabilities to these (French, Gabrielli 2004; Hoesli, Jani and Bender 2006). This approach can incorporate the probability of a resident departing in any given year and measure the resulting impact on the valuation determined. Practice based industry observation has noted the use of the Monte Carlo approach in retirement village DCF valuations by two organisations; namely a valuation firm undertaking valuations for not for profit and for profit clients and a funds management firm undertaking analysis for investment performance. However a normal distribution for resident duration was the prevalent methodology due to the lack of evidence as to the extent to the skewed distribution.

In the area of retirement village valuation methodology published writing to date has concentrated on the most appropriate methodology for the various stages of a village's operational life-cycle: development land; initial development; unsold units and operational (maturing and mature). The 
issue of valuation metrics has been considered with regard to escalation factors, the time period of the cash flow, the incorporation of a terminal value and the discount rate. The considerable variation between individual retirement villages results in an acceptance of a range of these variables and acknowledges the interrelationship between these components of the DCF including growth rates and the discount rate (McAuliffe 2012, Moshione 1992).

Listed Australian village operators disclose valuation metrics from their portfolios when reporting their financial performance. Following the acquisition of Australian Retirement Communities (ARC) in 2007 Stockland reported that the average resident duration for the 17 villages in the portfolio was 12 years (Stockland 2007). These metrics had changed little when in 2011, following the acquisition of the Aevum portfolio; in an investor briefing it was reported that a typical retirement village achieves maturity after 10 - 12 years from completion and that the average resident duration across an established retirement village portfolio was 12 years (Pitman 2011).

A portfolio includes new, maturing and mature villages and these do not necessarily present the same resident duration, a shortening of which was noted by FKP Property Group which reported an average resident duration of those residents who entered before 1990 of 9.7 years. For residents who entered in later years, this duration had reduced downward with those entering from 2001 to 2005 having stayed on average 3.6 years (FKP Property Group 2010). The assumptions in the Directors' valuations as of 30 June 2012 included a resident duration of 10 years for Independent Living Units (ILUs) and 4 years for Serviced Apartments (SAs) and a Discount Rate of 12.5\% (FKP Property Group 2012).

Accountants acting in advisory and agency capacity in the retirement village sector are in a position to view recent asset performance and purchasers' valuation metrics and have noted benchmark resident durations between 11 and 13 years (Willison 2012).

The focus of this paper is the duration of initial residents and rollover residents, in particular to establish whether there is a difference in mean duration between these two groups. The study has the potential to establish what the realistic maximum duration of an individual resident is and whether the distribution of resident duration is normal or skewed Furthermore the impact upon the estimated value of a retirement village using DCF analysis with a skewed duration distribution can be demonstrated.

\section{VALIDITY OF DATA}

As part of the research a database of Australian retirement villages operated under State and Territory retirement village legislation (DMF villages) has been compiled. Villages operated exclusively as rental seniors' accommodation have been compiled separately. Information on in excess of 2,000 DMF villages comprising over 120,000 ILUs has been recorded with information including the addresses, owner, operator, number of ILUs and SAs, number of bedrooms, commencement date, further development, tenure type, pricing and co-location with a Residential Aged Care Facility.

A summary of the total number of operational retirement villages identified in each state in contained in Table 2.

\begin{tabular}{lcccccccc}
\hline & NSW & VIC & QLD & SA & WA & TAS & NT & ACT \\
\hline Villages & 587 & 406 & 299 & 427 & 201 & 55 & 2 & 26
\end{tabular}

Australian Operational Retirement Villages by State Table 2 
The retirement villages analysed were selected for their period since initial development, older villages are able to provide a greater quantum of historical resident durations. However in sourcing the information the original data was scrutinised and transactions removed which did not conform to resident occupancy parameters. Transactions that were removed included the following.

- All transactions involving operators were scrutinised and it was noted that some operators (of Strata Title villages) purchase units from exiting residents hold these for a period ( $<1$ year), then sell to an incoming resident.

- Bulk transactions involving operators.

- Transactions with resident durations outside benchmarks and where the name of the historic incoming resident did not match the latter exiting resident.

- Transactions involving survivorship, namely a transfer from two residents to one of these two residents.

As a result approximately $20 \%$ - 30\% of original data was not included in the analysis.

\section{METHODOLOGY}

Development of a typical retirement village occurs over a period of years with individual stages ranging in number from $<10$ units to $>50$ units, in this way a village developer is able to meet market demand and minimise the expense of holding unsold stock. This results in each unit in the village having a unique sale and resale profile, with the first sale of a new unit to the initial resident followed by a series of secondary sales to rollover residents. A sample of this sale and resale profile is shown in Figure 1 with selected units in a hypothetical 100 unit village developed in four stages between 1987 and 1993. Each unit has one initial sale followed by a series of later sales resulting in a profile across the village over time of an assortment of initial and rollover residents still in situ.

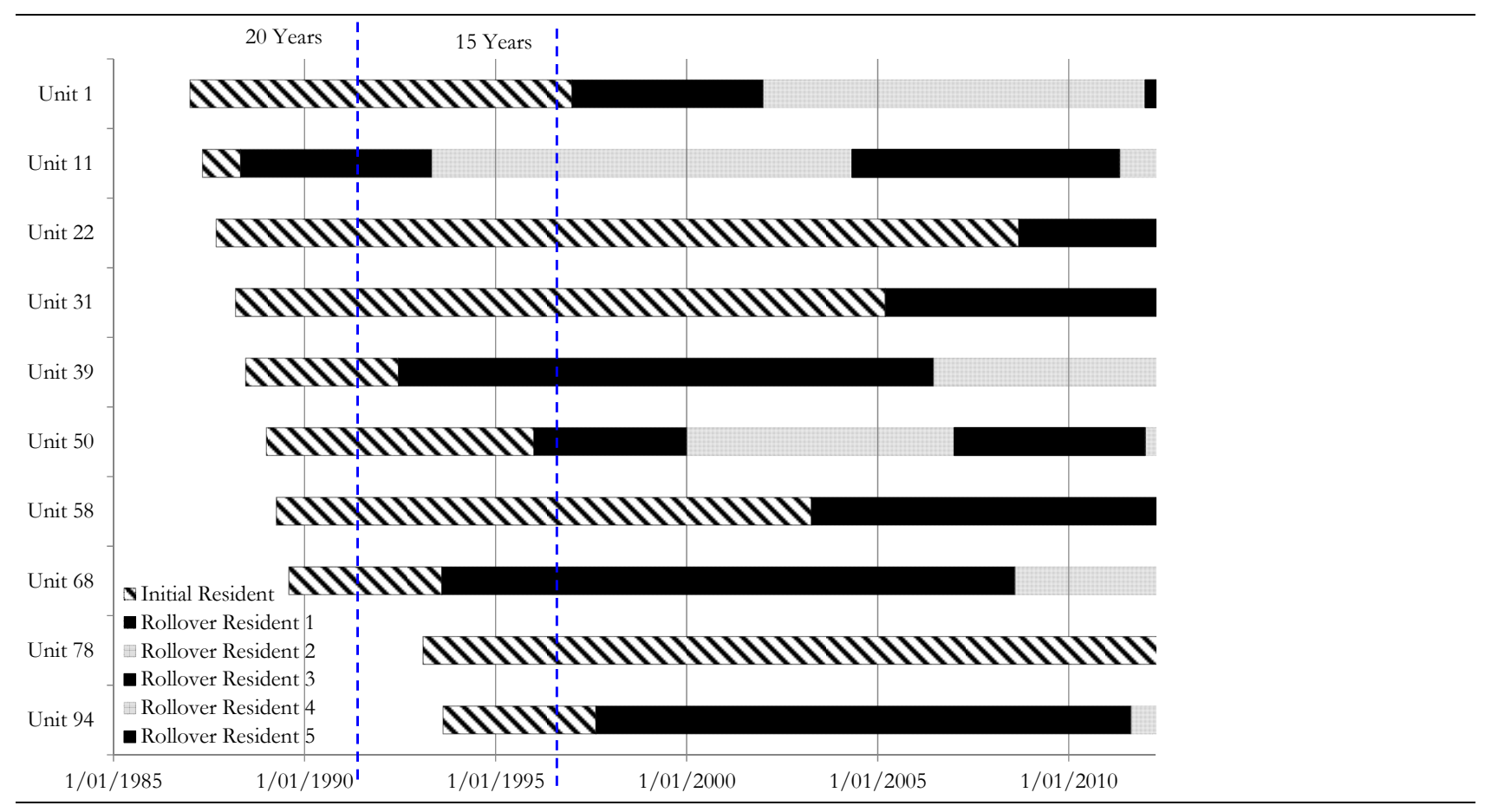

Sample Retirement Village Resident Duration for Initial and Rollover Residents Figure 1 
Historical data was collected for a sample of 30 individual villages, comprising in excess of 3,300 ILUs. These villages were selected for their size and length of period of operation facilitating the provision of meaningful data. Only ILUs were included in this analysis, SAs were identified and excluded as they are considered to present a different resident duration. Of the sample set, 15 of the villages were in New South Wales, 8 in Queensland and 6 in Western Australia; and 28 were operated under Strata Title tenure and 2 under Leasehold tenure. Information on all incoming and exiting residents in ILUs was then analysed and individual resident durations calculated and collated. Each transaction was categorised depending whether the resident was initial, rollover or current (still in residence).

In selected States third party data providers, RP Data and Espreon, distribute information on villages where tenure (resident interest) is registered on the title (Strata Title, Leasehold); this information includes resident name, date of commencement of interest (tenure), entry price and legal description. All data was sourced from these two providers. This enabled the maximum and minimum duration for each of these groups to be calculated, and are shown in Table 3.

\begin{tabular}{lcc}
\hline & Minimum & Maximum \\
\hline Initial Residents & $<2$ months & 25.4 years \\
\hline Rollover Residents & $<2$ months & 18.1 years \\
\hline Maximum and Minimum Duration of Initial and Rollover Residents: 30 villages, 1985 to 2012 \\
Table 3
\end{tabular}

This maximum duration creates a potential data distortion in analysing villages that have been operational for less than the maximum observed. To address this issue the data was further divided into subgroups depending upon the date of entry, a detailed as follows.

- All initial residents

- Initial residents entering before 1988 (potentially staying in excess of 25 years)

- Initial residents entering before 1992 (potentially staying in excess of 20 years)

- All rollover residents

- Rollover residents entering before 1997 (potentially staying in excess of 15 years)

The all initial residents and all rollover residents groups contain residents that did not have the potential to stay the maximum number of years therefore their presence skews these groups towards higher numbers of shorter durations. The three date limited groups, while comprising a smaller sample set, provide a comparison showing the duration distribution closer to the maximum potential period of stay.

Information on Current residents was compiled separately with the intention to form a basis of comparison as the resident schedule is often the main source of information provided to valuers by retirement village operators. Determining any relationship between Current residents' period of occupancy and historic durations is considered relevant and the subject of further study.

This information was then collated with the duration, measured in whole years, for every transaction, for each village for each of the five sample groups. Individual durations were recorded for each transaction (with no rounding) this enabled the mean and median duration to be calculated for each village, each data set and across all 30 villages. 


\section{DURATION OF INITIAL RESIDENTS}

The sample of 30 villages comprised in excess of 3,300 ILUs, of these 1,811 had initial residents who had both entered and exited the village providing the initial residents sample set; as stated earlier the maximum observed duration was 25.4 years and the minimum was $<2$ months. Not all 30 villages have been operating for the maximum period of time; 6 villages commenced operations before 1988 permitting residents in those villages to stay the maximum potential period; 19 villages had commenced operations before 1992 permitting their residents to stay at least 20 years. The mean and median durations and the Number of resident durations (Data Points) for each of these three groups are shown in Table 4.

\begin{tabular}{lccc}
\hline Sample Group & $\begin{array}{c}\text { Mean } \\
\text { (years) }\end{array}$ & $\begin{array}{c}\text { Median } \\
\text { (years) }\end{array}$ & $\begin{array}{c}\text { No. of Resident } \\
\text { Durations }\end{array}$ \\
\hline Initial Residents - All & 9.0 & 8.4 & 1,811 \\
\hline $\begin{array}{l}\text { Initial Residents - Entry before } \\
1992\end{array}$ & 10.9 & 10.5 & 801 \\
\hline $\begin{array}{l}\text { Initial Residents - Entry before } \\
1988\end{array}$ & 12.9 & 12.7 & 158 \\
\hline
\end{tabular}

\section{Mean and Median Durations and Number of Observations for the Three Initial Residents Groups: 30 villages, 1985 to 2012 Table 4}

The duration metrics observed for the initial residents - all group was a mean of 9.0 years and a median of 8.4 years; for the initial residents - Entry before 1992 was a mean of 10.9 years and a median of 10.5 years; and for the initial residents - Entry before 1988 was 12.9 years and a median of 12.7 years. The largest group was initial residents - all with 1,811 observations followed by initial residents - Entry before 1992 with 801 observations, not surprisingly the smallest group, with the greatest date limitation, initial residents - Entry before 1988 with 158 observations.

The mean duration, although not strictly within, conformed to the parameters stated by Stockland, FKP Property Group 2012 and the accountancy group, however with the exception of the initial residents - all group, was in excess of that quantum stated by FKP Property Group in 2010.

The opinion expressed by industry participants is that the resident duration does not follow the normal distribution curve but would be skewed towards the early years of occupancy (FKP Property Group, 2010). This would reflect that while some residents to stay for an extended period of time the majority stay for a shorter period. In each of the three sample groups the median is less than the mean for initial residents duration. A chart of relative frequencies of distribution of each of the three sample groups' Resident duration with the Length of Stay - Years is shown in Figure 2. 


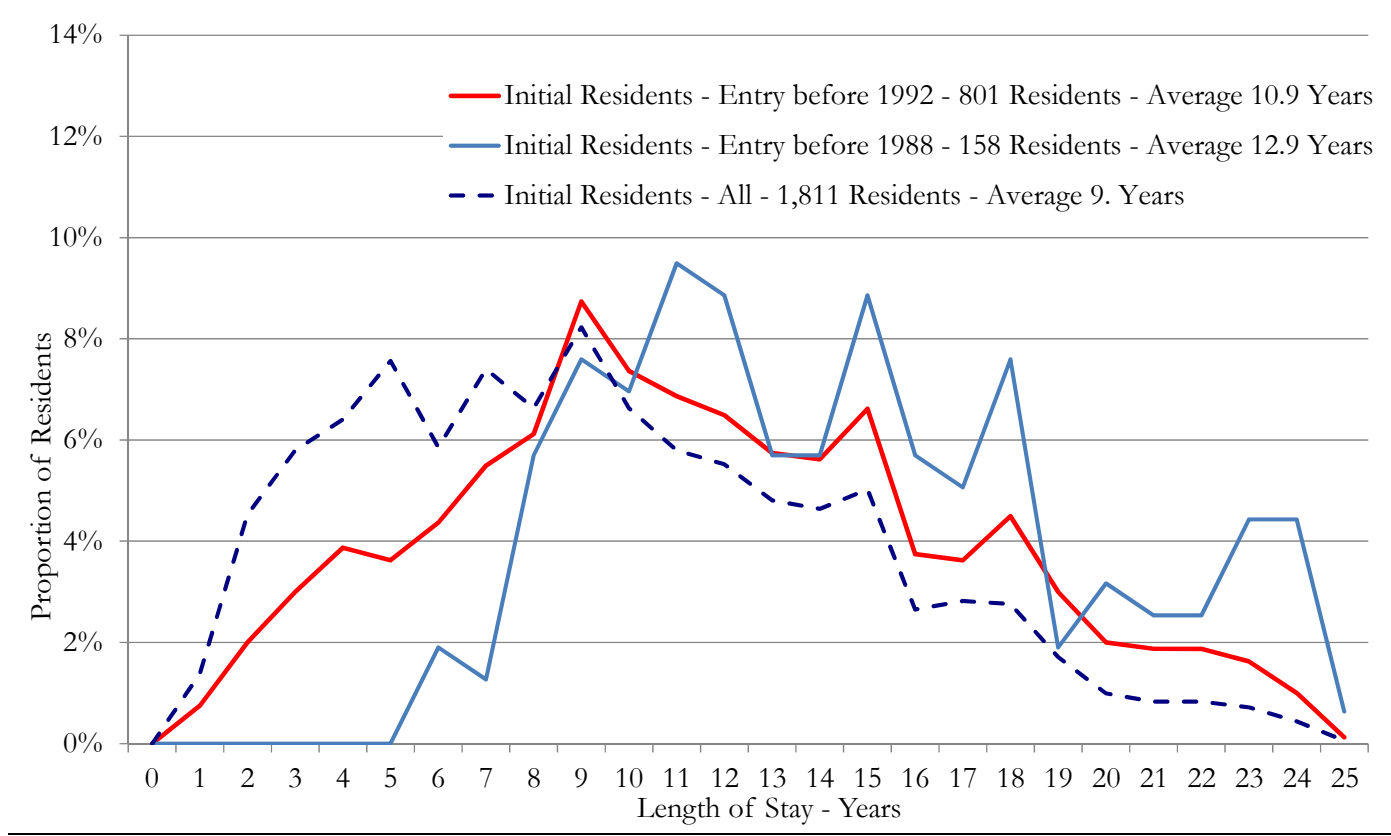

Relative Frequencies of Distribution of Duration for the Three Initial Residents Groups: 30 villages, 1985 to 2012

Figure 2

\section{DURATION OF ROLLOVER RESIDENTS}

Of the sample of 30 villages, 1,347 ILUs had rollover residents who had both entered and exited the villages providing this sample set with a maximum observed duration of 18.1 years and a minimum of $<2$ months. Again not all of the 30 villages had been operating for the maximum period of time, 20 villages had rollover residents who had entered the village before 1997 allowing these residents to potentially stay for at least 15 years. The mean and median durations and the Number of resident durations (Data Points) for both of these groups are shown in Table 5.

Sample Group $\begin{gathered}\text { Mean } \\ \text { (years) }\end{gathered} \begin{gathered}\text { Median } \\ \text { (years) }\end{gathered}$ No. of Resident Durations

\begin{tabular}{|c|c|c|c|}
\hline Rollover Residents - All & 5.3 & 4.5 & 1,347 \\
\hline Rollover Residents - Entry before 1997 & 6.9 & 6.3 & 301 \\
\hline
\end{tabular}

Table 5

The duration metrics observed for the rollover residents - all group was a mean of 5.3 years and a median of 4.5 years and for the rollover residents - Entry before 1997 was a mean of 6.9 years and a median of 6.3 years. The largest group was rollover residents - all with 1,347 observations followed by initial residents - Entry before 1997 with 301 observations. 
The mean duration for the two groups of rollover resident ranges between $40 \%$ and $76 \%$ of the mean duration for the three groups of initial residents; this indicates a significant difference in mean duration between these two types of residents. The mean durations for rollover residents are greater than those reported by FKP Property Group in 2010 of 3.6 years which was measured for residents who had entered their villages between 2001 and 2005.

The difference in mean duration between initial and rollover residents reflects industry opinion of the difference in duration between these two types of residents. The quantum of this difference has never been previously publicly quantified.

Again similar to the previous sample groups the distribution of duration displays a skewed profile for rollover residents - all the median is 4.5 years, less than the mean of 5.3 years; and for rollover residents - Entry before 1997 the median is 6.3 years, less than the mean of 6.9 years. A chart of the relative frequencies of distribution of the two sample groups' resident duration with the Length of Stay - Years is shown in Figure 3. This skew is more pronounced when compared with the relative frequencies of distribution for initial residents; this would indicate a different profile of occupancy between these two types of residents.

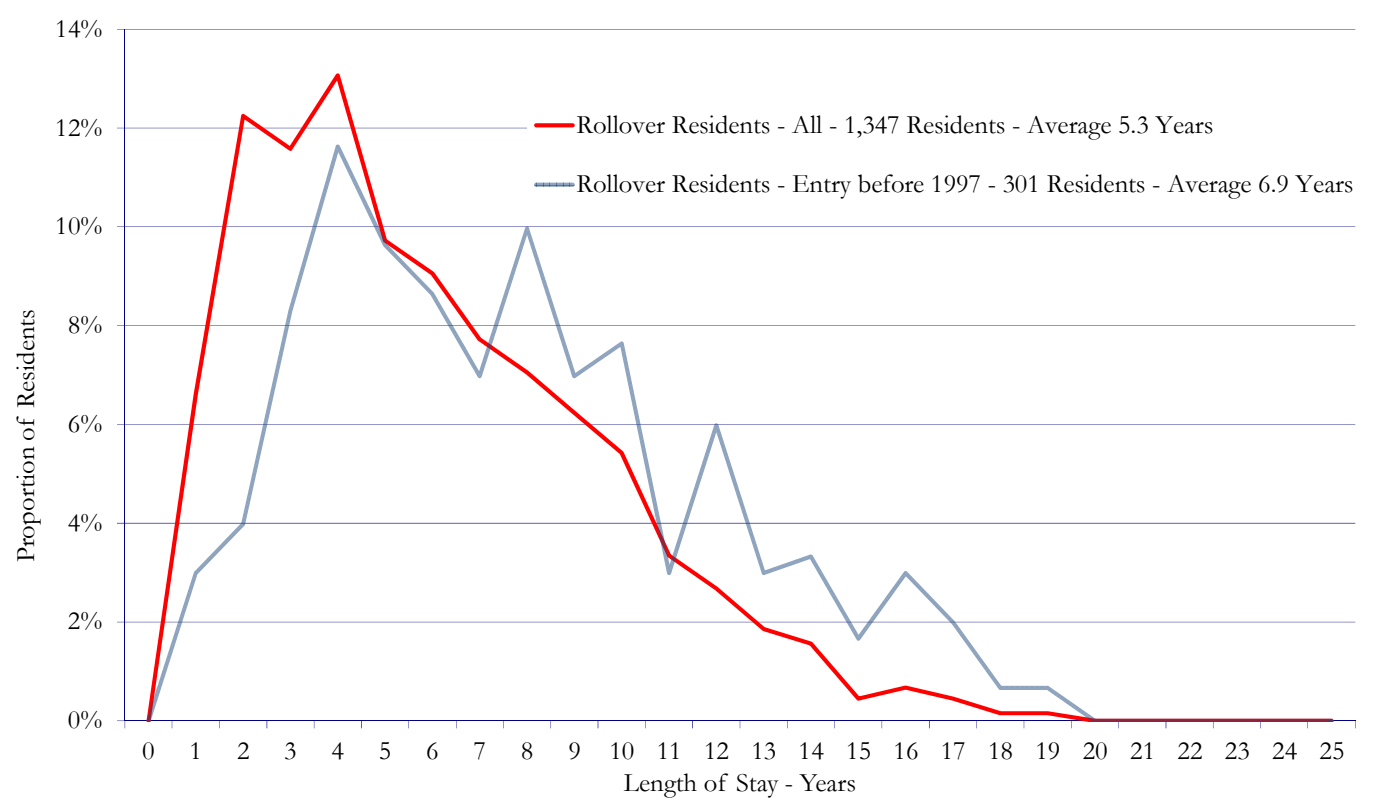
Relative Frequencies of Distribution of Duration for the Two Rollover Residents Groups:
30 villages, 1985 to 2012

Figure 3

\section{IMPACT ON VALUATION OF A DMF CONTRACT}

As discussed previously there are two main components to the DMF, one based on an annual percentage cumulating after a period of years multiplied by either the incoming purchase price or that paid by the next resident and a share in the capital gain between these two prices. The capital gain sharing component can only be estimated based on the probability of future growth rates, however where the annual percentage is based on the incoming purchase price this quantum can be determined while the timing is unknown. This can be used to show the impact of the timing of a resident departure on the value of the DMF contract (Brehm, 2010). 
The following example is of a DMF contract of an ILU with the following components and valuation metrics.

Purchase Price $\quad \$ 100,000$

Annual Percent $\quad 3 \%$ per annum to a maximum of $30 \%$ after 10 years

Discount Rate $\quad 12.5 \%$

Utilising this example a profile of the DMF due to the operator can be calculated for each year of the resident contract, this is shown in Figure 4. The cumulative value of the DMF the operator (DMF) shows the absolute value of the DMF for each year if the resident were to leave that year. The present value of the DMF (PV of DMF) shows the present value of this cumulative DMF each year (again if the resident would leave that year). This cumulative DMF plateaus at its maximum in year 10 however the present value of the cumulative DMF reaches a maximum in Years 8 and 9 and then declines into the future.

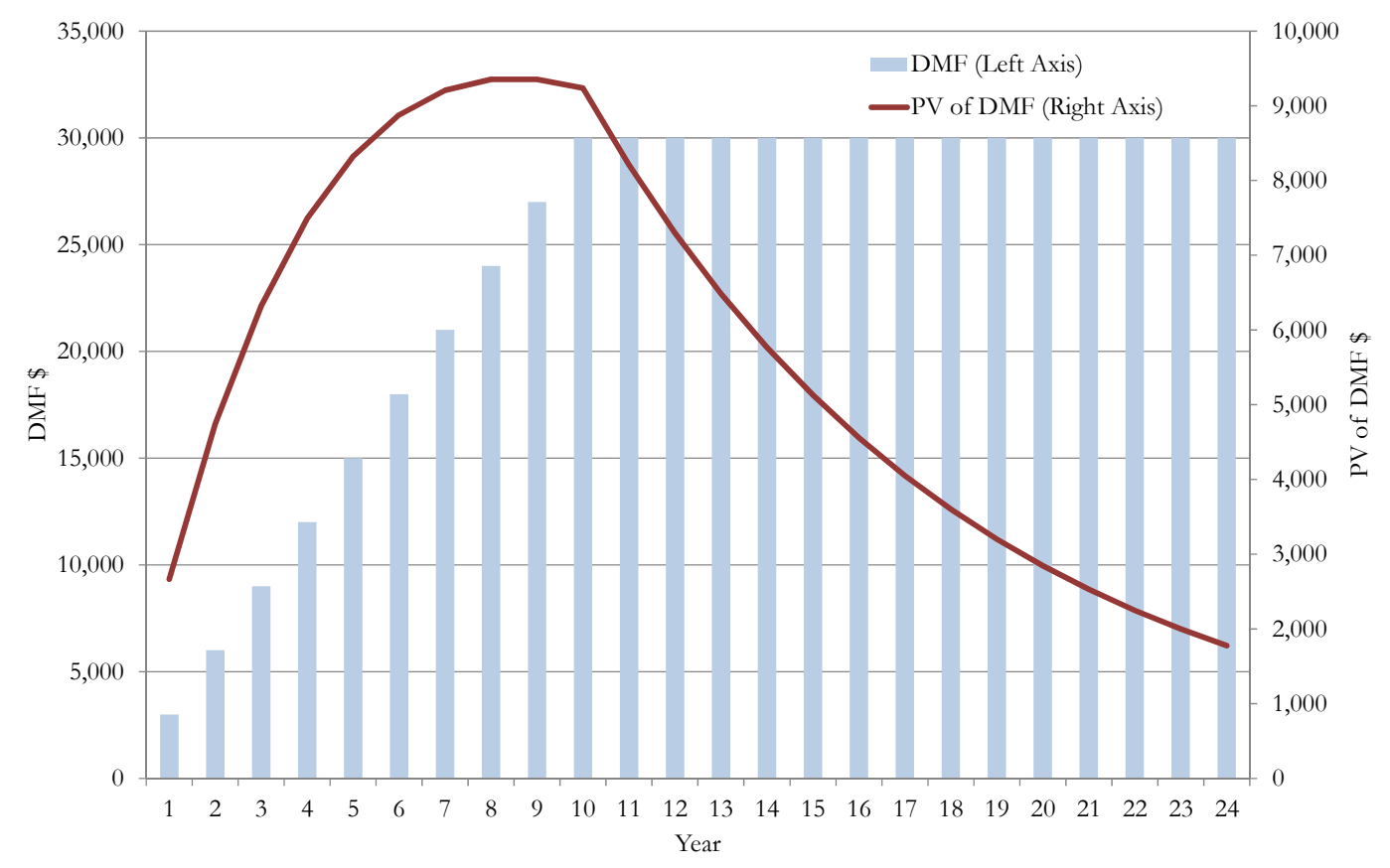

\section{Cumulative and Present Value of a Sample DMF Contract Figure 4}

Utilising the relative frequency information from the two largest sample sets (initial residents - all and rollover residents - all) the probability of resident departing at any one year has been established. The application of this probability shows the difference in present value between the two types of residents. This is shown in Figure 5. 


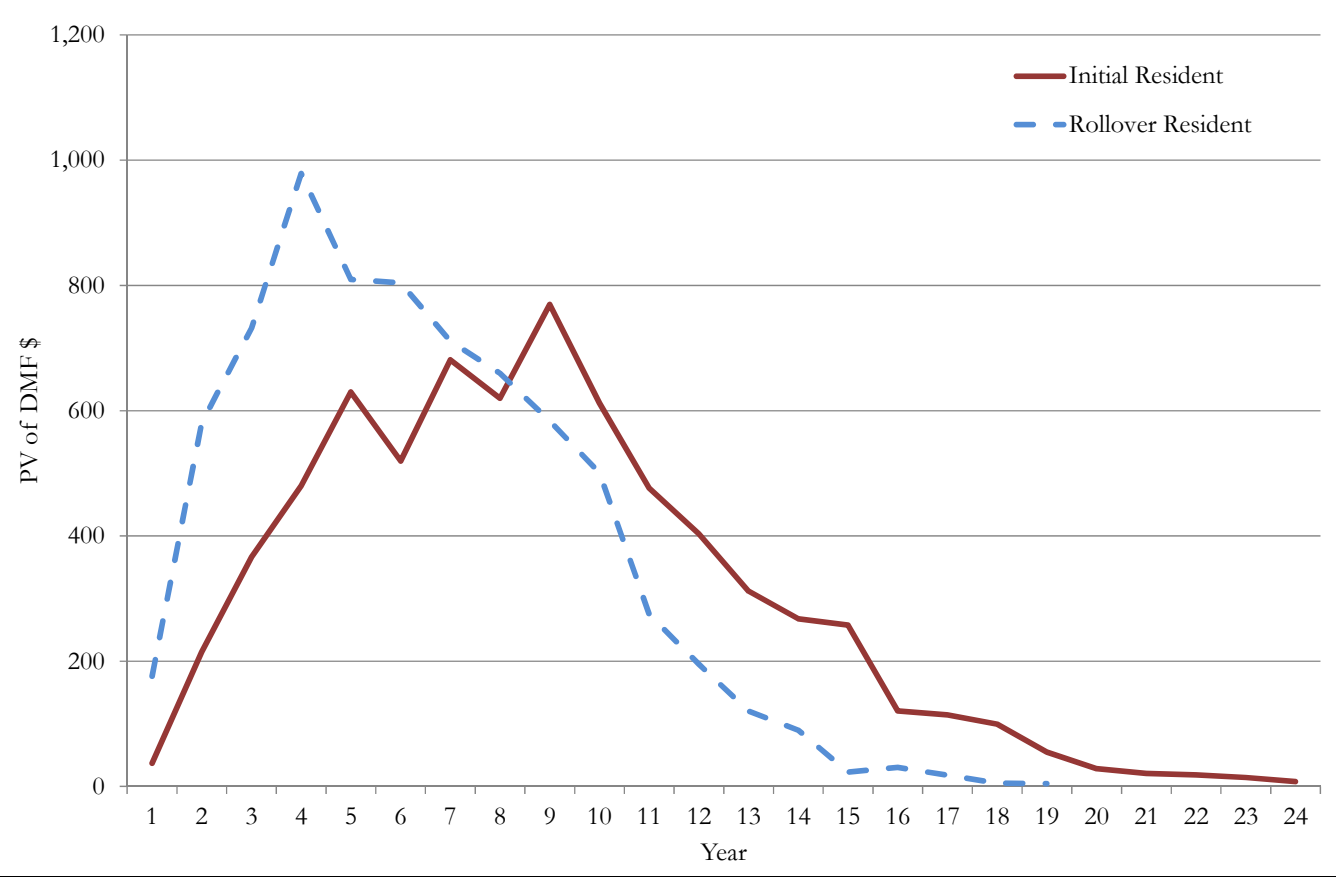

\section{Present Value of a DMF Contract and Probability Based on Resident Type for Initial Residents-All and Rollover Residents-All: 30 villages Figure 5}

With this example the most desirable year (for the operator) for an initial resident to depart is year 9 which coincides with the maximum value of the DMF contract; whereas the most desirable year for a rollover resident to depart is year 4 .

The implications in undertaking a valuation is that depending on the most probable year of exit there is a significant variation in the present value determined. These differences have the potential over a larger village and the timeframe of the DCF analysis, to compound further and result in significant potential variation in any probable valuation derived.

Coupling the probability of departure for both initial and rollover residents it is also apparent that the DMF contract does not fully profit from the potential longer time frame of residents. By achieving a cumulative plateau of the DMF in year 10 the lack of any further growth in DMF revenues from residents that remain longer than this period results in a potential underperformance of a retirement village. Practice based industry observation has noted utilisation of this longer resident duration in only one village which achieved a "maximum" DMF of 30\% after 10 years, each year thereafter a smaller compounding annual percent $(0.25 \%)$ was charged with no maximum cap.

\section{CONCLUSION}

This paper addresses the lack of public quantifiable data on which retirement village valuation metrics can be based. The major finding is that there is a difference in resident duration between initial and rollover residents. Initial residents have a mean duration of between 9.0 years and 12.9 years and rollover residents have a mean duration of between 5.3 years and 6.9 years. Furthermore the frequencies of distribution for all sample groups show that this is a skewed distribution as opposed to a normal distribution with medians less than the mean. 
Further research is required to produce statistically meaningful resident duration distributions which could then be incorporated into valuation analysis. This could also consider determining whether there is a relationship between resident duration and life expectancies.

The implication of this difference is also in regard to the DMF fee which best matches projected resident durations. Villages that are currently under development and are selling new ILUs to initial residents would achieve a greater projected DMF income to the operator by incorporating a fee structure which utilises the longer duration of these residents. Operators of established villages would achieve greater projected DMF income by incorporating a fee structure which achieves the maximum corresponding to the median duration of this group.

This study is based on Australian villages which commenced operations in the 1980s and 1990s and carries the implicit assumption that there has been little change in retirement village residents since this period. Residents entering retirement villages are doing so later in life and often staying for longer periods than previously observed which has been attributed to the care and support that can be provided through retirement village accommodation (RVA and Deloitte 2010). It is proposed to further augment this analysis by comparing the relative frequencies of distribution of individual years of entry since the 1980s to determine whether there has been any significant change in resident duration over time.

The results from the analysis show the different durations between initial residents and rollover residents, this has been sourced from third party data providers. This analysis is purely quantitative, qualitative analysis comprising interviews with village operators may determine further factors to be incorporated into the analysis and is considered a further stage in the research.

A valuer, when instructed to provide a valuation of a retirement village, is usually provided with a current resident schedule which is often the only piece of information provided on which to base the average resident durations in the DCF analysis. Determining whether there is a relationship between the period in situ of current residents and historic resident durations would be useful as it would enable more an accurate valuation analysis to be undertaken with the limited information provided.

\section{REFERENCES}

Armitage, P., Berry, G., and Matthews, J. N. S., 2002, Statistical Methods in Medical Research. Blackwell Publishing.

Brehm C, 2010, Retirement Village - Valuation of the DMF Contract, Aviiid Third Age Living, Sydney.

Cradduck L and Blake A, 2012, The Impact of Tenure Type on the Desire for Retirement Village Living, Presented at the 18th Annual Pacific Rim Real Estate Society Conference, University of South Australia, Adelaide.

Elliott P, Earle G and Reid R, 2002, The Valuation of Self-Funded Retirement Villages in Australia: Analysis, Reliability and Investment Valuation Methodology, paper presented at the Pacific Rim Real Estate Society Conference 21 - 23 January 2002, Christchurch, New Zealand.

FKP Property Group, 2010, Retirement as an Asset Class A Fresh Perspective (ASX Submission), FKP Property Group, Brisbane.

FKP Property Group, 2012, Appendix 4E and 2012 Financial Report (ASX Submission), FKP Property Group, Brisbane. 
French N and Gabrielli L, 2004, The uncertainty of valuation, Journal of Property Investment \& Finance, Vol. 22, Iss: 6, pp 484-500.

Hatcher J, and O’Leary J, 1994, Valuing Retirement Villages, The Valuer \& Land Economist, Vol 33, No. 1, pp $34-46$.

Hoesli M, Jani E and Bender A, 2006, Monte Carlo simulations for real estate valuation, Journal of Property Investment \& Finance, Vol. 24, Iss: 2 pp 102-122.

McAuliffe B, 2010, Resident-funded retirement village valuations: complications with the application of the DCF, Australia and New Zealand Property Journal, Vol. 2, No. 8, pp 493-493.

Moshione P, 1992, Retirement Villages, The Valuer and Land Economist, Vol. 32 No. 1, pp 14-17 \& 29.

Pitman D - Stockland CEO, Retirement Living, 2011, Retirement Living Investor Briefing (ASX Submission), Stockland, Sydney.

RVA and Deloitte, 2010, Caring for Older Australians - Submission to the Productivity Commission, Retirement Village Association Ltd, Melbourne.

Stockland, 2007, Acquisition of Australian Retirement Communities (ARC) (ASX Submission), Stockland, Sydney.

Towart L C, 2005, Retirement Villages A Sunset Industry in a Sunrise Situation, Australian Property Journal, Vol 38, No 5, pp 350-361.

Towart L C, 2009, Current Issues in the Analysis and Valuation of Established Retirement Villages, Australian Property Journal, Vol 2, No 3, pp 164-167.

Willison M, 2012, Profiling the market in the Retirement and Aged Care Sectors, Ernst \& Young, Melbourne. 